Research Article

Open Access

Anna Halicka*, Jacek Zyga

\title{
The Consequences of Non-Uniform Founding of Concrete Tank in Weak Wet Subsoil
}

https://doi.org/10.2478/sgem-2019-0023

received June 9, 2019; accepted August 7, 2019.

Abstract: The article presents problem of non-uniform foundation of structures in weak wet subsoil. The problem is illustrated with the case study of two-chamberreinforced concrete water tank constructed in 1920s of 20th century, which cracked during construction. Under part of foundation, where the peat was found, the concrete piles were introduced.

The results of five-year measurement of crack widths with crack gauges and geodesic measurements of vertical displacement of tank were presented. These results indicate that the tank is not stable and part of broken tank supported on piles is movable.

On the basis of the presented data, the general conclusions concerning the non-uniform founding of tanks are formulated.

Keywords: concrete tank, stability, differential settlement, cracks, levelling.

\section{Introduction}

Concrete liquid tanks seem to be rigid, heavy and insensitive to differential settlement. The practice shows, however, that tanks founded in the layered subsoil may be subjected to differential settlement, particularly if one on the layers is of low strength and low stiffness. The non-uniform distribution of stress transferred onto the ground strongly contributes to the increase in differential settlement, for example, stress under foundations of columns and walls are different from stress under bottom slab and stress under full chamber is different from stress under empty one in the multi-chamber tank. The problem increases if the underground water is present.

*Corresponding author: Anna Halicka, Politechnika Lubelska, Lublin, Poland, E-mail: a.halicka@pollub.pl Jacek Zyga, Politechnika Lubelska, Lublin, Poland
Some examples of differentially settled tanks are described for cylindrical $[5,12]$ as well as for prismatic tanks $[2,3,9]$. In the tank described below (Figs. 1 and 2), one more reason intensifying the differential settlement is present. The foundation is non-uniform: a part of the tank is founded on piles, whereas the rest of it is founded directly on the bottom slab.

The differential settlement may cause cracks, opening of the expansion gaps and even tilt or rotation of whole tank or its parts. Such damages are unwanted because

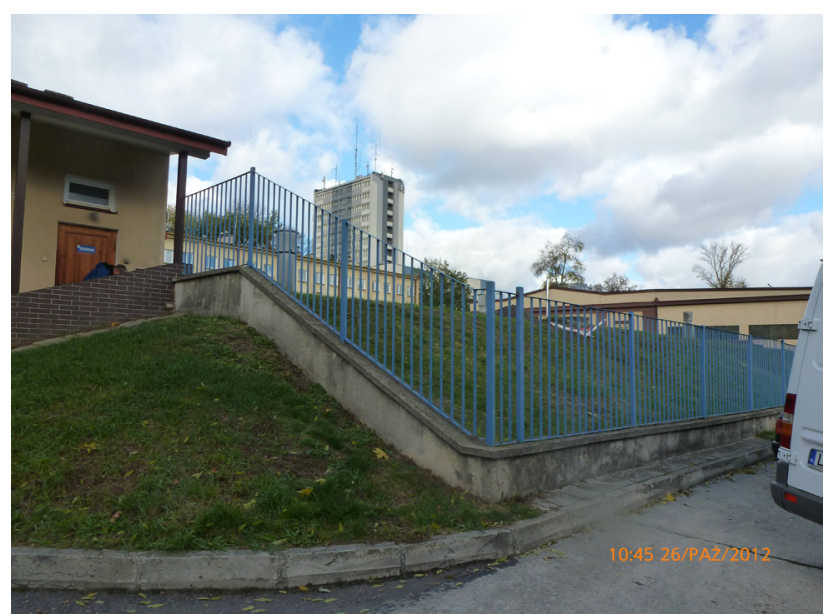

Figure 1: The outside view of water tank.

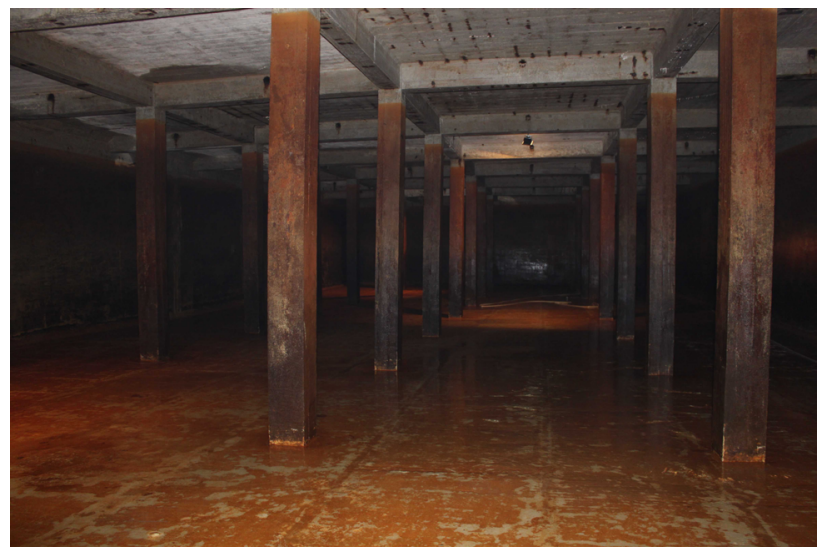

Figure 2: The interior of concrete tank. 


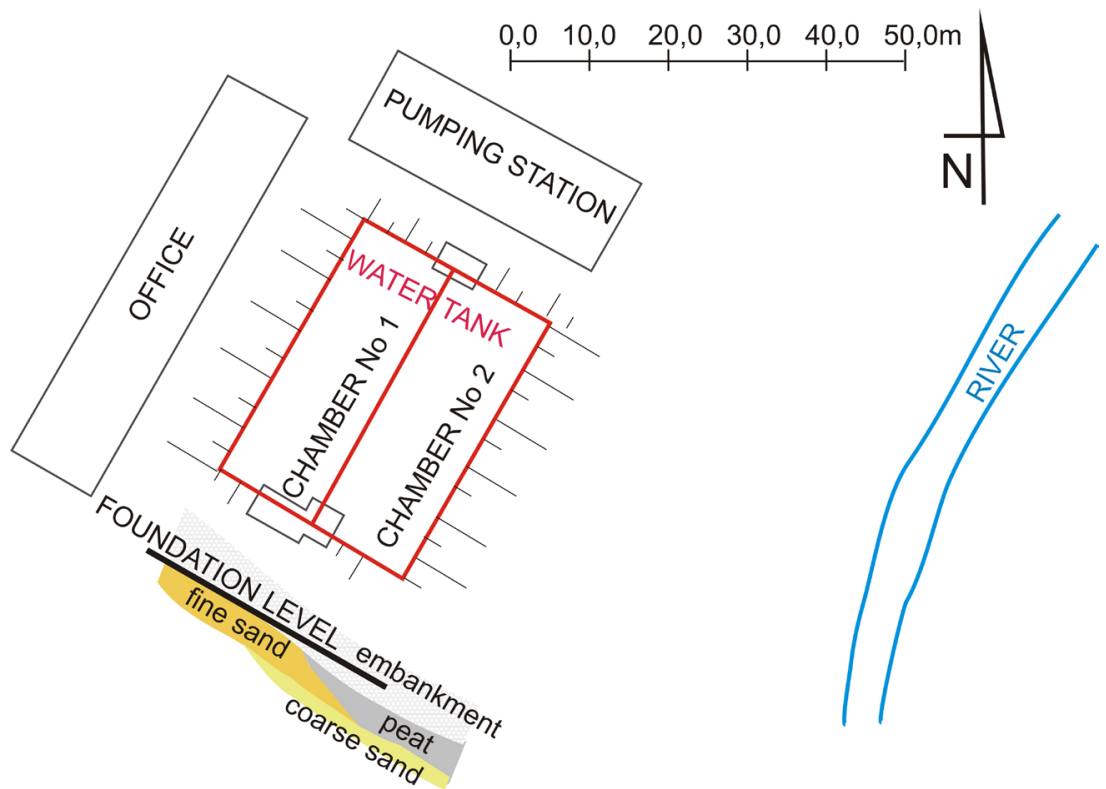

Figure 3: The location of water tank in relation to the river and the buildings of water supply plant with the scheme of geotechnical layers.

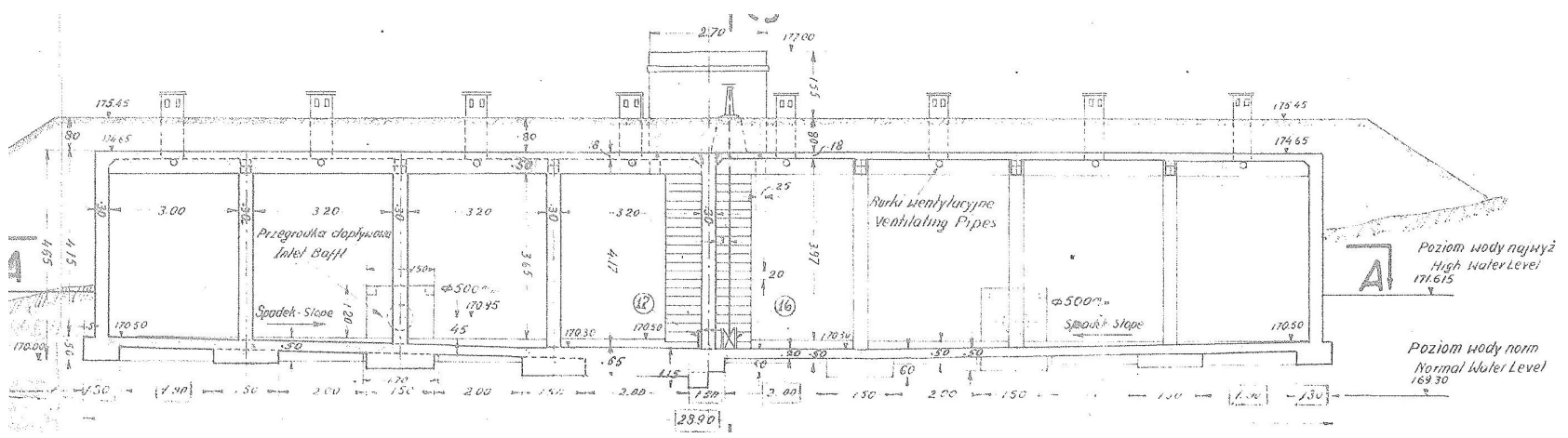

Figure 4: The original design drawing of tank cross section [1].

the water tanks should be watertight. The decision of the repair procedure should be undertaken based on the information whether the settlement is finished or if the tank is stable. The examination of cracked water tank stability performed for that purpose is described in the following sections.

\section{Description of analysed water tank}

\subsection{Location and geometry}

The analysed two-chamber reinforced concrete underground water tank is localised $50 \mathrm{~m}$ away from the river. The capacity of each chamber equals to $1617 \mathrm{~m}^{3}$, and its dimension is $13.5 \mathrm{~m} \times 37.8 \mathrm{~m} \times 4.0 \mathrm{~m}$. The thickness of backfill is about $0.80 \mathrm{~m}$.
The tank was built in 1920s and its cracking was reported just after construction. The history of tank construction and damage was recognised based on the original design drawings and data found in the town archive [8] and described in details in the article [4]. The original design drawing of tank cross section [1] is shown in Figure 3.

The tank is covered by cast in situ concrete roof slab of square segments, supported by crossing beams, which are rested on the columns and outer and inner walls. Reinforced concrete cast in situ walls are fixed in the continuous foundation and columns are fixed in the spot foundations. These foundations are connected monolithically with bottom slab. The level of bottom slab down surface is higher than that of down surface of spot and continuous foundations, whereas their upper surface is on the same level (Fig. 4). 


\subsection{Subsoil conditions}

Geotechnical tests show that in this region (Fig. 3), the upper subsoil layer of up to 5 -m thick is an embankment consisted of humus dust, sand and stones. Under the embankment in the west part of tank, the moderately compacted fine sand is deposited, and under it, there is moderately compacted sand of bigger particles. This part of tank is founded on the upper surface of sand. Towards the river and towards east direction, between embankment and sand, the mud and peat (wet but not highly plastic) are present. In the town archives, there is an information dating from the construction times [8] that pumping station adjacent in this side to the tank is founded in the water logged peat on the concrete foundations supported on the 340 timber piles.

In the design cross section (Fig. 4), underground water level is not provided. There is only an information that normal level of the river equals to $169.30 \mathrm{~m}$ above sea level (which is lower than foundation), and maximum river level equals to $171.615 \mathrm{~m}$ above sea level (which is higher than foundation). After river regulation in 1970s, fluctuations of river level were diminished.

The underground water level has changed since the years. During geotechnical testing in 1991, the underground water level was stabilised from 167.27 up to $168.29 \mathrm{~m}$ above sea level. Therefore, it was more than $1 \mathrm{~m}$ lower than that of tank foundation. Meanwhile, in 2000, in the place of bottom slab depression inside the tank, two holes were found, from which the water came out to the surface under pressure. This indicated the rise of underground water level. What is more, the water appeared in the adjacent pump station, also proving the underground water level rise. In the spring of 2010, the owner started the piezometric measurement of underground water level (Fig. 5).

The rise of underground water level may not only have the character of the short-term fluctuations (e.g. depending of the river level) but may connected with general trend of water level change in this region of the town - rising of underground water level was observed within a radius of several hundred metres away from the water supply plant. The exploitation of deep water and fluctuations of depression funnel are the possible reason for this trend. Three wells from the turn of 19th century worked here since first 25 years of 20th century. Two of them restarted in 1952 year, and in 1980s, there were four wells (in Fig. 4, the very low level of underground water is visible). Owing to diminishing water consumption, which happens in the middle of 1990s, only two wells are open nowadays, and pumps are not working continuously.

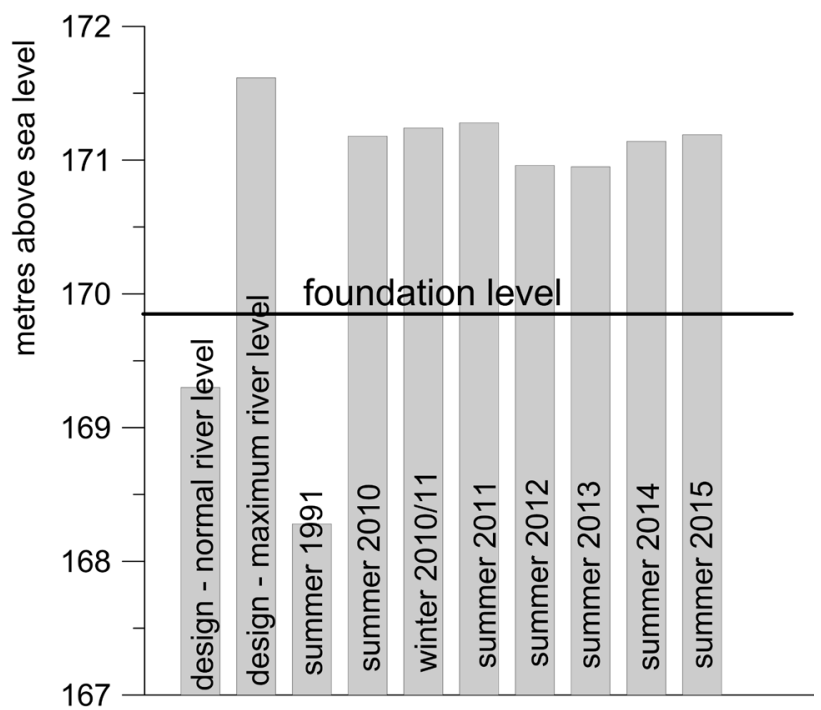

Figure 5: The levels of underground water in relation to foundation level: the water in the river in accordance to design drawings (normal and maximum) and the water level found nowadays (maximum).

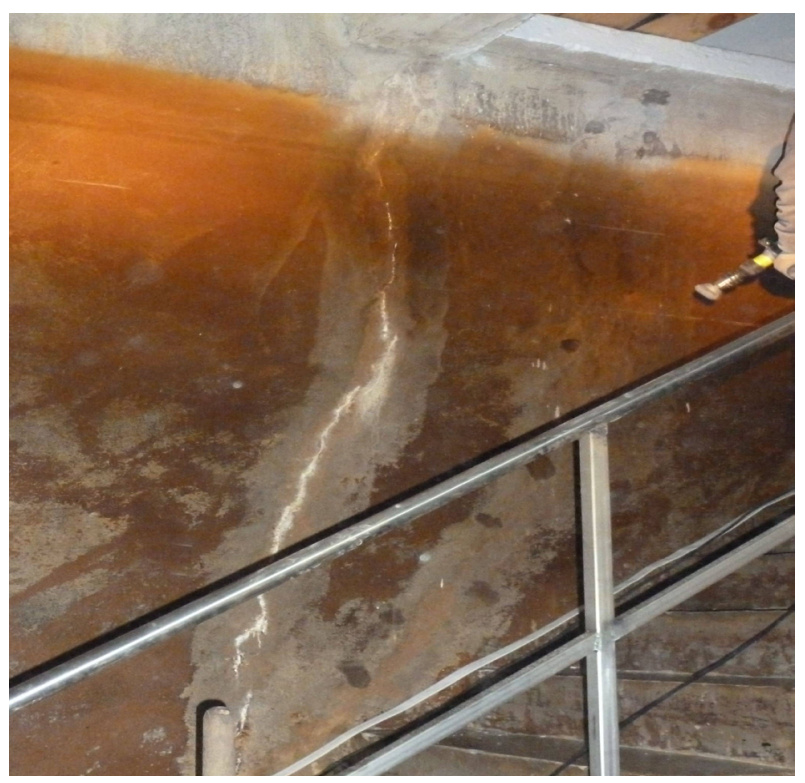

Figure 6: The exemplifying crack with salting out in the longitudinal partition wall.

\subsection{Crack pattern}

Four characteristic locations of cracks were found in the tank (Figs. 6 and 7):

- intensive cracks in the roof slab in chamber No. 1, inclined in relation to wall axes at an angle of $45^{\circ}$; some of them propagate into beams or longitudinal 
partition wall and some of them propagate into roof slab of chamber No. 2;

- two types of cracks in longitudinal partition wall: vertical cracks beginning from the roof cracks and diminishing their width towards bottom and inclined wide (even $1.5 \mathrm{~mm}$ ) cracks located in the middle of wall length;

- vertical cracks in longitudinal outer wall of chamber No. 1 and vertical or inclined cracks in south-west transverse outer wall in both chambers;

- crack in the bottom slab in chamber No. 2 along the longitudinal partition wall, deflected in the chamber corner towards south direction.

Several cracks were repaired. The most of them remains closed, but in some of them, in the longitudinal partition wall, the secondary cracking and salting out appeared.

\section{Failure and repair of tank under construction}

The troubles concerning the tank foundation occurred during its construction yet. The evidence of these troubles constitutes the handwritten remarks made with pencil on the original design drawing (Fig. 8b). In the chamber No. 1 next to the transverse north-east wall, the circles were drawn and described as follows: 'sequence of additional pile holes to determine peat line. Some may not be needed' (notation ' 1 ' in Fig. 8b). There was, most likely, the program of additional geotechnical testing. In the town archives, there is information that 'the tank was built without tentative tests, and as the consequence the tank settled demonstrating cracks' [8]. The next hand-drawn element nearby the longitudinal partition wall (notation ' 2 ' in Fig. $8 \mathrm{~b}$ ) is described as 'additional piles'.

The above-mentioned handwritten remarks were made probably before concreting of the continuous walls foundation of chamber No. 2 (partition and outer wall) as well as the spot foundations and after finding out the peat in the excavation. In the original drawing of tank strengthening (Fig. 8a), the piles located on the both sides of the longitudinal walls making a pair and four piles crosswise connected under some spot foundations are present. It is not known what type of piles was designed. It can be supposed that there were timber piles, similar to that in the adjacent pumping station. Additional

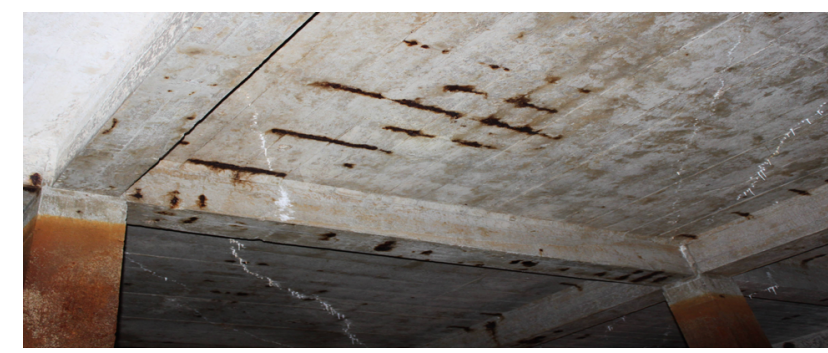

Figure 7: The exemplifying crack with stalactites of salting out in the roof slab.

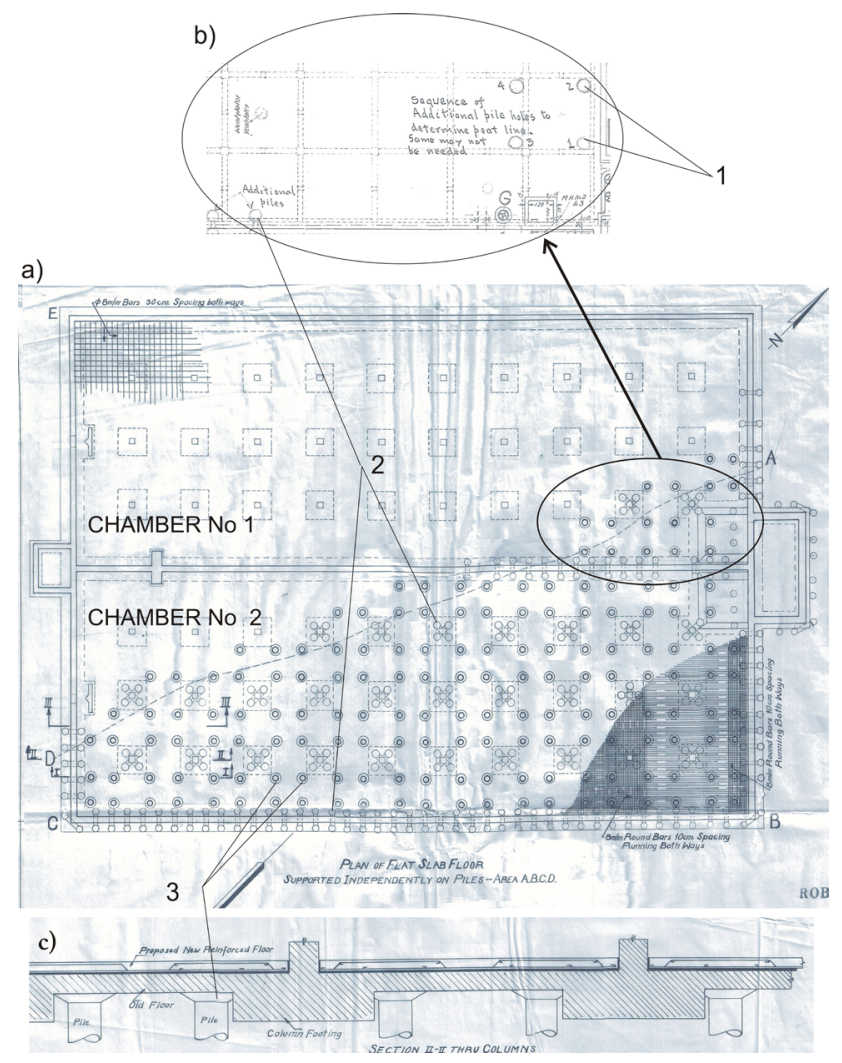

Figure 8: Original design drawings concerning the tank strengthening [1]: (a) location of piles in the $A B C D$ region, (b) hand-made remarks, (c) cross section of bottom slab with concrete piles; (1) location of holes planed for peat level determination, (2) 'additional piles' (probably timber piles), (3) concrete piles under foundation slab.

strengthening was executed probably after finishing the tank construction. It was written in the town archives that 'there was a necessity to strengthen of the foundation with concrete piles' [8]. In Figure 8a and 8c, the design sketch of this strengthening is quoted [1]. The piles were designed not under whole tank but only in the $\mathrm{ABCD}$ region - under chamber No. 2 and under small part of chamber No. 1. The 
a)

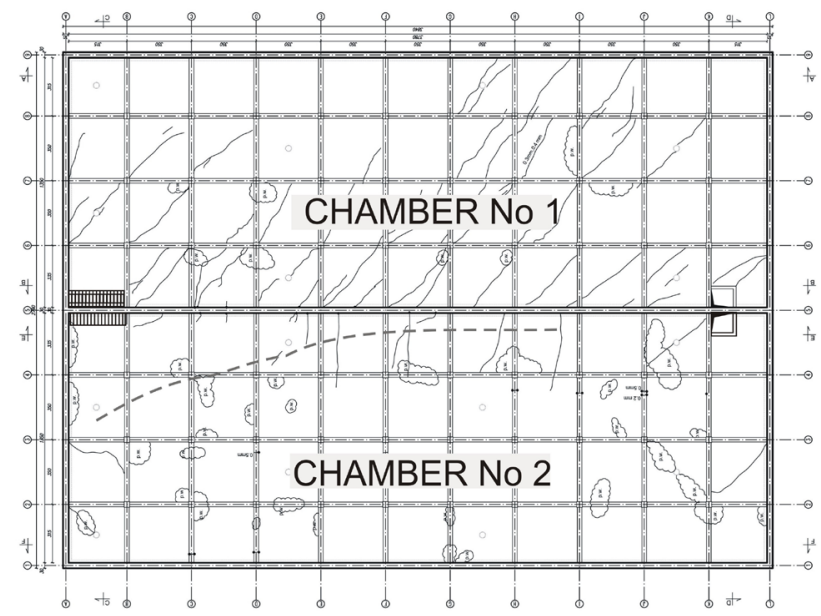

LEGEND:

- cracks in the roof slab

...- - crack in the bottom slab

- leakage

Figure 9: Crack pattern (a) versus region with piles (b).

piles were located nearby the corners of spot foundations and a new bottom slab was supported on them (notation ' 3 ' in Fig. 8a and 8c).

Finally, on the basis of the analysis of Figure 8 , it can be supposed that there are two types of piles under tank: piles made during construction under some foundations (probably timber piles) and concrete piles nearby the corners of some spot foundations supported the bottom slab. The tank owner and the experts preparing the previous technical assessments were not aware of existence of these piles.

The crack pattern indicates the reason of cracks, which is the non-uniform tank settlement. In Figure 9, the crack pattern is compared with the region, where piles were added. The cracks in roof slab and walls indicate the 'break' of tank as a consequence of non-uniform settlement and separation the part with piles from part without piles. This is confirmed by the crack in the bottom slab in chamber No. 2, which is almost in line with the piles region border and then runs along the edge of foundation of longitudinal partition wall.

\section{Measurement of crack width and tank vertical displacement}

In order to assess the stability of the tank, in 2012, the monitoring of concrete cracks was started, based on the results obtained from first measurement. b)
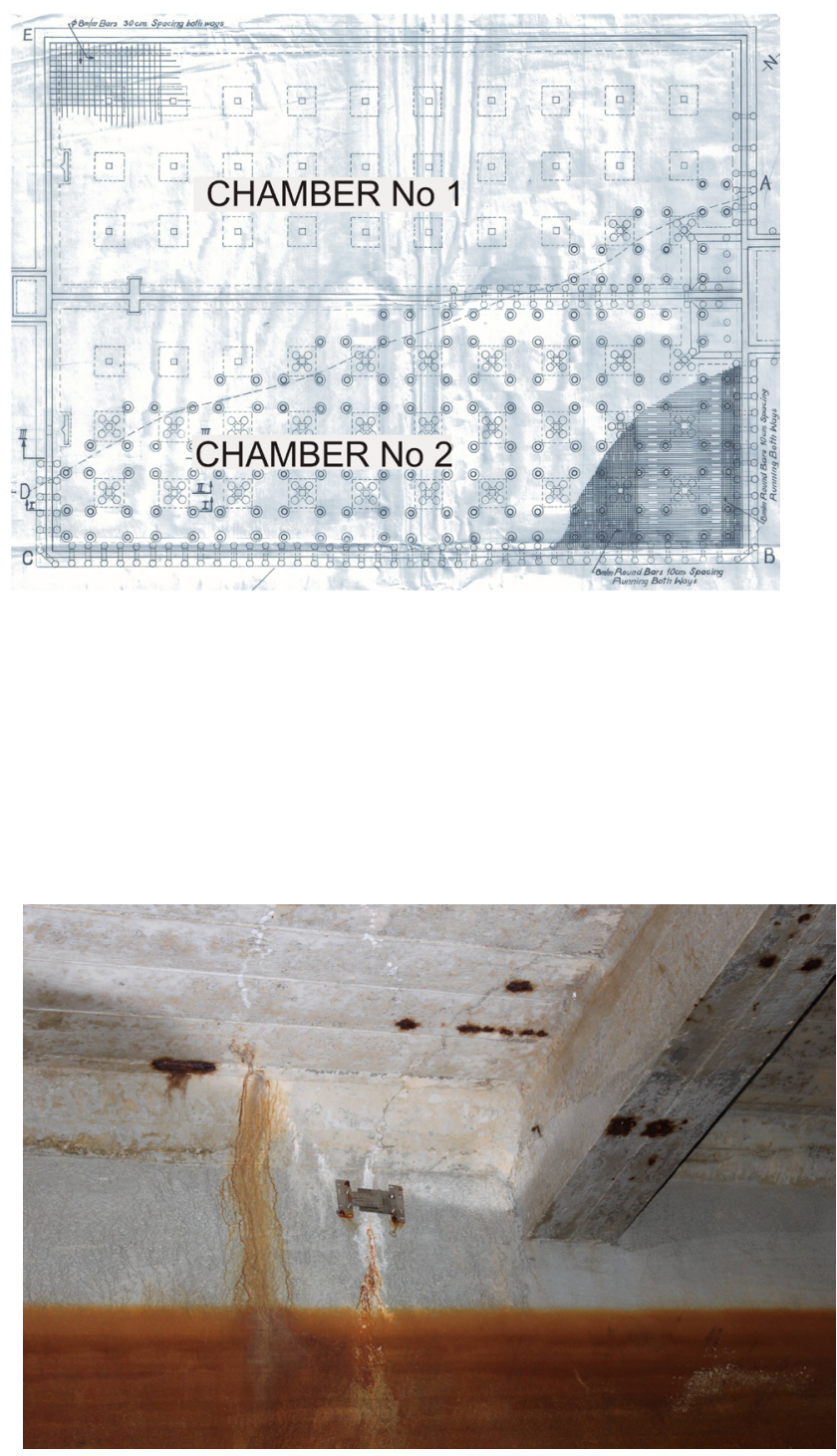

Figure 10: The crack width gauge fixed to the longitudinal partition wall.

The crack width was measured with eight crack gauges allowing to assess the changes in crack width as well as displacement along the crack (Fig. 10). The location of the gauges is shown in Figure 11. The measurement results are shown here as well. An analysis of the data from Figure 11 indicates that the crack measured with gauge No. 4 in the chamber No. 1 is immovable. The remaining cracks in this chamber show little changes in width (up to $0.2 \mathrm{~mm}$ ). They also show very little displacement along crack (up to $0.05 \mathrm{~mm}$ ), except the gauge No. 6 fixed next to longitudinal partition wall in the region with piles. This gauge was found to get displaced along a crack of $0.85 \mathrm{~mm}$ between 2016 and 2017. The crack width in chamber No. 2 changed to a maximum of $0.30 \mathrm{~mm}$. The displacement 


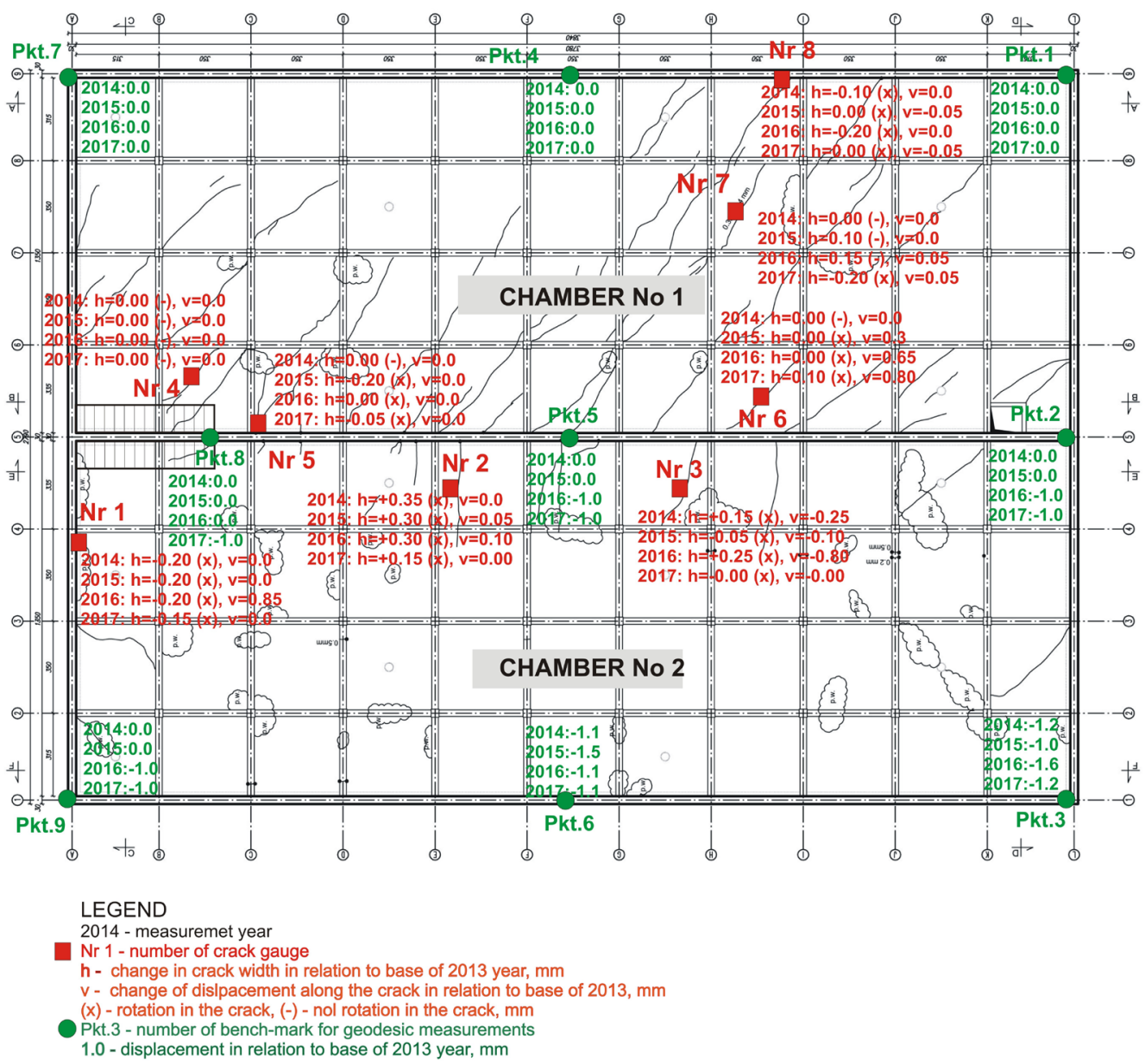

Figure 11: The location of crack gauges and places of vertical displacement surveying and the measurement results in 2014-2017.

along crack was equal up to $0.25 \mathrm{~mm}$, except the crack in the transverse south-west wall measured with gauge No. 1 (0.85 $\mathrm{mm}$ in 2016).

The results of crack width measurement may be recapitulated as follows. The cracks, particularly cracks locating next to boundary of piles region, are not stabilised. Most intensive movement was observed in 2016. It is difficult, however, to compare their values to the measurement of underground water level, because piezometric tests were stopped in this year.

At the same time, the vertical displacement was measured. Nine controlled points were laid out on the upper surface of the tank roof slab along the axes of longitudinal walls. Their arrangement is shown in Figure 11. Owing to the fact that the tank was covered with embankments, special structures constituting the control points were designed. They were fixed to the roof slab and protruded over the embankment (Fig. 12). This enabled a direct measurement of control points without roof slabs uncover.
Moreover, the control levelling network based on benchmarks fixed to the walls of surrounding buildings was set up (Fig. 13). Vertical displacement was calculated in the local height system $\left(\mathrm{H}_{\mathrm{RP} 1}=100.000 \mathrm{~m}\right)$, as relative displacement between the first and next elevations in several surveying epochs [6]. Elevations of each controlled point were determined by direct levelling based on the benchmarks of confirmed stability. The precise digital level instrument named Trimble DiNi was used. In each surveying epochs, benchmarks No. 1 and No. 2 only were designated as stable ones.

The five-year levellings revealed movements of some controlled points; however, their displacement did not exceed $1.6 \mathrm{~mm}$. Nevertheless, the movement of controlled points located along the axis of outer longitudinal wall of Chamber No. 2 (point No. 3, No. 6 and No. 9) was confirmed. Such conclusion was derived based on the accuracy of the displacement estimation (in various epochs of measurements, levelling accuracy ranged from 


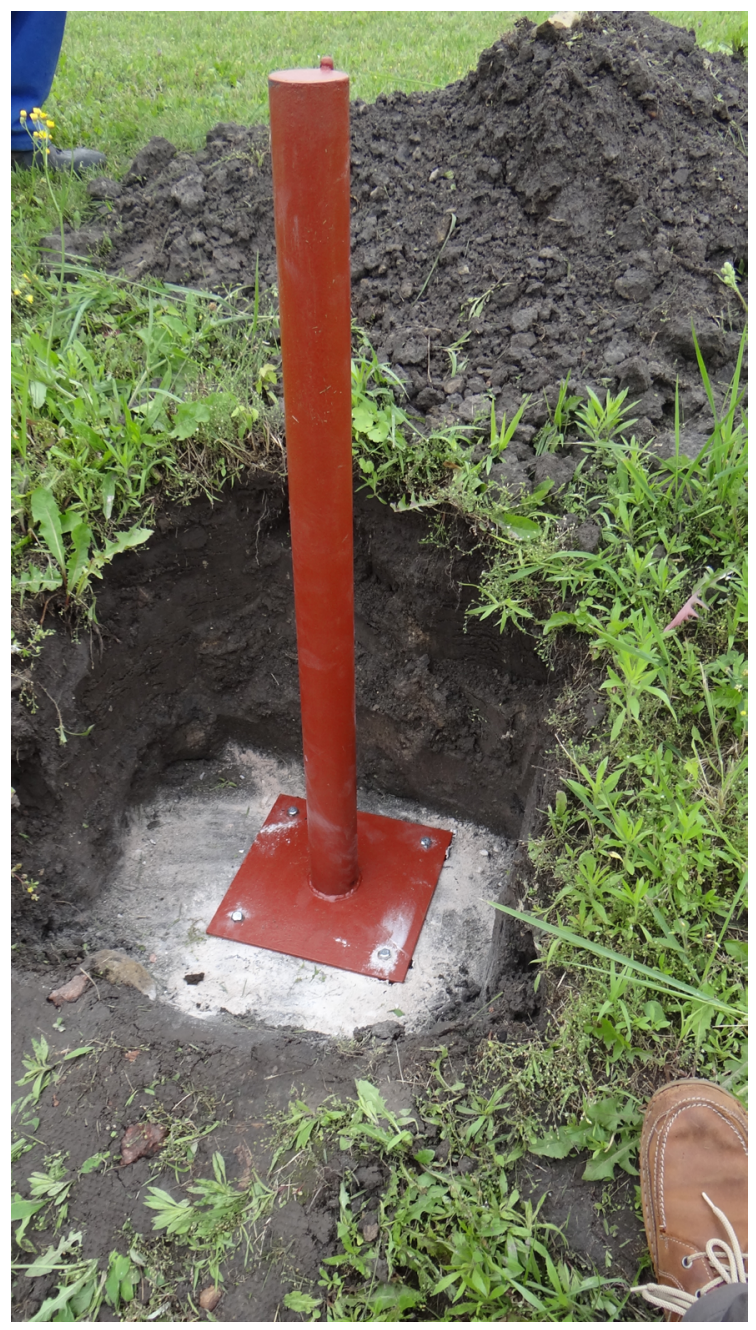

Figure 12: The structure of controlled point whilst fixing to the upper surface of the roof slab.

0.2 to $0.7 \mathrm{~mm}$, depending on the measurement conditions) and confirmed by the ratio of the displacement $(\mathrm{d} H)$ to the error $\left(\sigma_{\mathrm{d}} H\right)-\left|\mathrm{d} H / \sigma_{\mathrm{d} H}\right| \in(2.1 ; 5.7)$. The control points along the longitudinal partition wall (point No. 5 and No. 8) as well as control points along the outer wall of the Chamber No. 1 (point No. 1, No. 4 and No. 7) showed the movement considered as negligible $\left(\mathrm{d} H / \sigma_{\mathrm{d}} H<2.1\right)$. This observation connected with small absolute displacement $|\mathrm{d} H|<0.5 \mathrm{~m}$ proves that these points are stable. Nonzero values of their displacement may be considered as the effect of the measurement inaccuracy, however, being within the limits of the average error of a single observation.

The movement of point No. 2 cannot be clearly interpreted. Its observation was interrupted in 2014 with the damage of the measuring mark. The re-start of the measuring in the subsequent epochs showed, however,

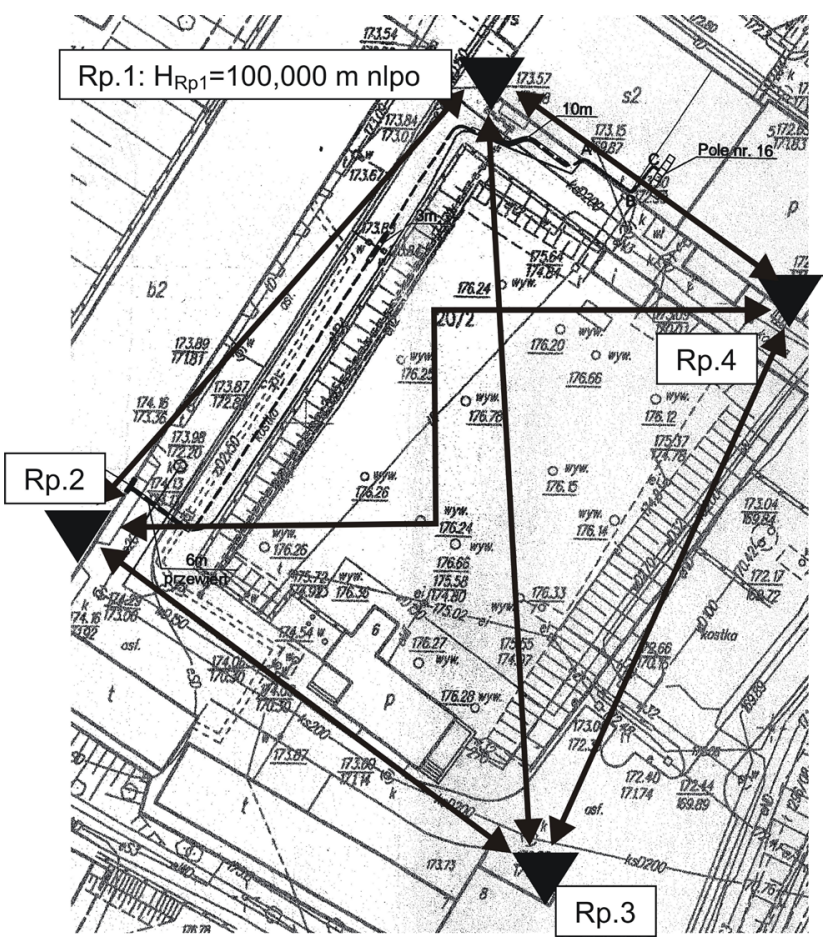

Figure 13: The benchmark control levelling network.

that point No. 2 goes down to $-1.0 \mathrm{~mm}$. This suggested that this point also belongs to the zone subjected to the settlement.

The results of the changes in vertical confirmed displacements are shown in Figures 11 and 14.

The results of tank vertical movement estimation may be recapitulated as follows. There is a trend of the vertical displacement of some controlled points in relation to the initial position. There are minor but clear changes. The changes in position of point No. 3, No. 6 and No. 9, located along the axis of the outer longitudinal wall, were revealed in all the measurements.

\section{Conclusions}

The five-year crack width measurement and vertical tank displacement surveying show that part of tank is not stable yet. The part of tank supported on the piles is subjected to minor but clear settlement. This is manifested by vertical displacement of walls in chamber No. 2 and changes in crack width.

The analysis of the presented case study leads to the formulation of the following conclusions:

1. The credible assess of the old structures' safety demands not only the visual inspection, but studying 

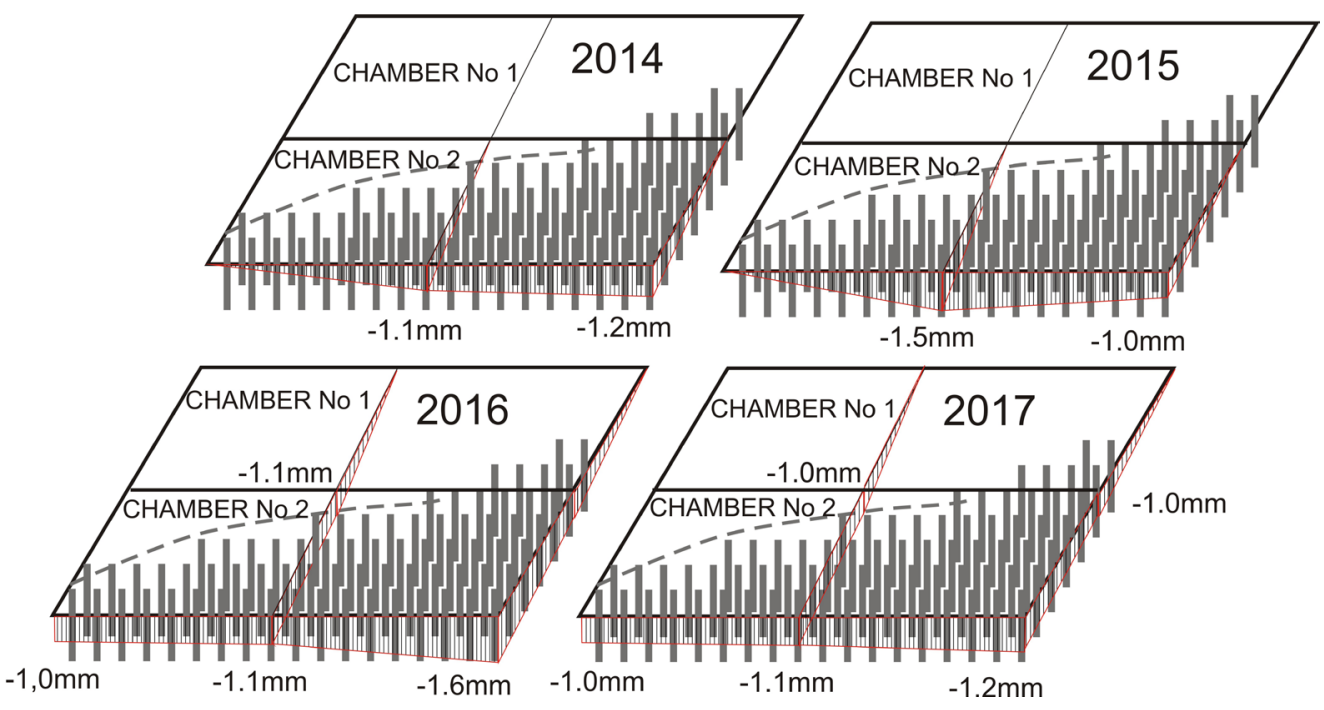

Figure 14: Displacement of controlled points.

the archival drawings and even studying the documents in town archive office is also necessary. This can bring unknown or forgotten facts from the construction time to light and help to understand the reasons of failure. Such procedure is recommended by EN ISO 13822:2010 code [7].

2. The precise settlement analysis should be performed during calculation and design of concrete tanks, particularly for the tanks found in weak wet soil.

3. The strengthening of foundation by supporting them on piles is not always effective. The differential vertical displacement may occur, particularly in the case of layered weak subsoil and fluctuations of underground water level. Periodical emptying of one of the chambers is a conducive factor. This should also be carefully analysed whilst planning the foundation strengthening.

4. The application of piles under part of structure, without dividing it with expansion gaps, may cause the break of the structure. However, expansion gaps are not favourable in tanks because of the difficulties with water tightness. What is more - separated parts may displace in relation to one another and gaps may open. Therefore, such solution should be avoided.

5. The non-uniform settlement constitutes the imposed action that results in the internal forces in the structure. When the tension stress exceeds the tension strength of concrete, the cracks appear. The cracks are open, and because of the fluctuations in the settlement, the width of cracks is changeable.

6. The displacement of separated parts of analysed tank is not large. Therefore, the further use of tank was allowed but the repair works were recommended. The injection of cracks with elastic material dedicated for open movable cracks was recommended. This ensures the tank water tightness as well as further movement of separated parts in relation to each other without waterproofness loss.

\section{References}

[1] Archival drawings from the design and strengthening documentation prepared in 1927 year.

[2] Buczkowski W., Czajka S., Kowalski J.: About the reasons of failure of reinforced concrete prismatic tank (in Polish), Inżynieria i Budownictwo nr 12/2003, pp. 683-685.

[3] Calderon P.A., Adam J.M., Payá-Zaforteza I.: Failure analysis and remedial measures applied to a RC water tank, Engineering Failure Analysis, 16/2009, pp. 1674-1685.

[4] Halicka A, Franczak-Balmas D., Jabłoński t.: The history of construction and failure reinforced concrete water tank from the interwar period in 20th century (in Polish), Inżynieria i Budownictwo nr 9/2014, pp 480-483.

[5] Hamid B., Varaksin S.: Ground Improvement of Tank Foundations in the Middle East, International Congress and Exhibition "Sustainable Civil Infrastructures: Innovative Infrastructure Geotechnology” GeoMEast 2017: Soil Testing, Soil Stability and Ground Improvement, pp 194-209.

[6] Hermanowski A.: Measurement of vertical displacement (in Polish), Warsaw, 1993.

[7] ISO 13822:2010: Basis for design of structures. Assessment of existing structures.

[8] Michałowski St.: One hundred years of modern water supply system in Lublin 1899-1999, MPWiK Lublin 1999.

[9] Seruga A., Kaźmierczak Sz.: Failure and repair conception of reinforced concrete sewage tank (in Polish) Przegląd Budowlany 4/2012 pp. 46-49. 
[10] Stanciu A. Boti N., Lungu I., Donciu O.: Case Study of a

Water Tank Behaviour on an Improved Collapsible Soil, $60^{\text {th }}$ Conference on Case Histories in Geotechnical Engineering, Arlington 2008, pp. 7.21a-1 - 7.21a-10.

[11] Szymczak Cz., Iwicki P., Mikulski T.: The analysis of failure of biological reactor in Gdańsk-East sewage plant (in Polish), Proceedings of XXIII Conference „Failures of structures 2007”, pp.773-780.

[12] Yoshizawa M., Onimaru S., Uchida A., Hatanaka M.: A study on liquefied ground disruption effects on liquid storage tank behavior 12 WCCE 2000, pp. 1430.1-1430-8. 